\title{
Advanced Gel Electrophoresis Techniques Reveal Heterogeneity of Humic Acids Based on Molecular Weight Distributions of Kinetically Inert $\mathrm{Cu}^{2+}-$ Humate Complexes
}

Kazuki Marumo, ${ }^{\dagger}$ Atsumasa Matsumoto, ${ }^{\dagger}$ Sumika Nakano, ${ }^{\dagger}$ Masami Shibukawa, ${ }^{\dagger}$ Takumi Saito,,+

Tomoko Haraga, "and Shingo Saito ${ }^{\dagger, *}$

†Graduate School of Science and Engineering, Saitama University, 255 Shimo-Okubo, Sakuraku, Saitama 338-8570, Japan

¥Graduate School of Engineering, Tokyo University, 7-3-1 Hongo, Bunkyo-ku, Tokyo 113-8656, Japan

IDepartment of Decommissioning and Waste Management, Japan Atomic Energy Agency, 2-4

Shirakata, Tokai-mura, Naka-gun, Ibaraki 319-1195, Japan

17 pages, including 1 table and 9 figures 


\section{Contents}

\section{Other chemicals and instruments}

\section{Results}

Table S1. Characterization of humic acids employed in this study.

Figure S1. Outline of our MICS-PAGE/metal-detection PAGE/UV-Vis/EEM-PARAFAC methodology.

Figure S2. Electropherograms for HA separation PAGE and metal-detection PAGE for an ultrapure water sample.

Figure S3. Core consistency as a function of the number of components in PARAFAC modeling.

Figure S4. Results from the split-half analysis.

Figure S5. Typical MW distributions of $\mathrm{Cu}^{2+}$ for DHA, IHA, and LHA.

Figure S6. EEM spectra of the five florescence components.

Figure S7. EEM spectrum of the $26^{\text {th }}$ MW fraction of an IHA sample (a, left) and EEM spectrum obtained by recombining the five PARAFAC components for this fraction, a residual EEM of the 28th fraction of $\mathrm{Cu}^{2+}$-LHA using four-component PARAFAC model, and residual EEMs compared with original EEMs for IHA.

Figure S8. EEM spectra for HAs and $\mathrm{Cu}^{2+}-\mathrm{HA}$ complexes for PAHA, DHA, IHA, and LHA.

Figure S9. Abundances and populations of the five fluorescent components in each MW fraction for DHA, IHA, LHA, $\mathrm{Cu}^{2+}-$ DHA, $\mathrm{Cu}^{2+}-\mathrm{IHA}$, and $\mathrm{Cu}^{2+}-$ LHA. 


\section{Other chemicals and instruments}

A MW protein standard (3-color Prestained XL-Ladder, Apro Science, Tokushima, Japan) was used as a MW marker. Solutions of 10\% ammonium persulfate (APS; Kishida Chemical Co. Ltd., Osaka, Japan) and $N, N, N^{\prime}, N^{\prime}$-tetramethylethylenediamine (TEMED; Acros Organics, Geel, Belgium), used for acceleration of polymerization, were prepared at the time of use.

A thermostatted water bath (LTB-125, AS ONE, Osaka, Japan) and an incubator (MIR-252, SANYO Electric, Osaka, Japan) were employed to control the temperature of the slab gels.

\section{Results}

Table S1. Characterization of humic acids employed in this study. ${ }^{1}$

\begin{tabular}{|c|c|c|c|c|c|c|c|c|c|c|c|c|c|}
\hline \multirow[t]{2}{*}{ Name } & \multirow[t]{2}{*}{ Origin of $\mathrm{HA}$} & \multicolumn{5}{|c|}{ Elemental composition(\%) } & \multicolumn{4}{|c|}{ 13C NMR carbon distribution (\%) } & \multicolumn{3}{|c|}{ Acidic functional group (mmol/g) } \\
\hline & & Ash & C & $\mathrm{H}$ & $\mathrm{O}$ & $\mathrm{N}$ & carbonyl & carboxyl & aromatic & aliphatic & carboxyl & phenol & $\begin{array}{c}\text { nitirogen- } \\
\text { bearing }\end{array}$ \\
\hline PAHA & Peat & 1 & 56 & 5 & 39 & 1 & 4 & 16 & 56 & 24 & 8.04 & 3.84 & 0.77 \\
\hline $\mathrm{DHA}$ & Forest soil & 1 & 53 & 5 & 37 & 4 & 3 & 11 & 33 & 30 & 8.07 & 3.16 & 6.05 \\
\hline IHA & Volcanic ash soil & 1 & 55 & 4 & 37 & 4 & 4 & 15 & 37 & 23 & 7.68 & 3.46 & 5.22 \\
\hline LHA & Lignite & 3 & 64 & 4 & 31 & 1 & 8 & 15 & 58 & 15 & 7.46 & 2.31 & 1.38 \\
\hline
\end{tabular}

1) S. Lukman et al., Geochimica et Cosmochimica Acta, 2012, 88, 199-215. 


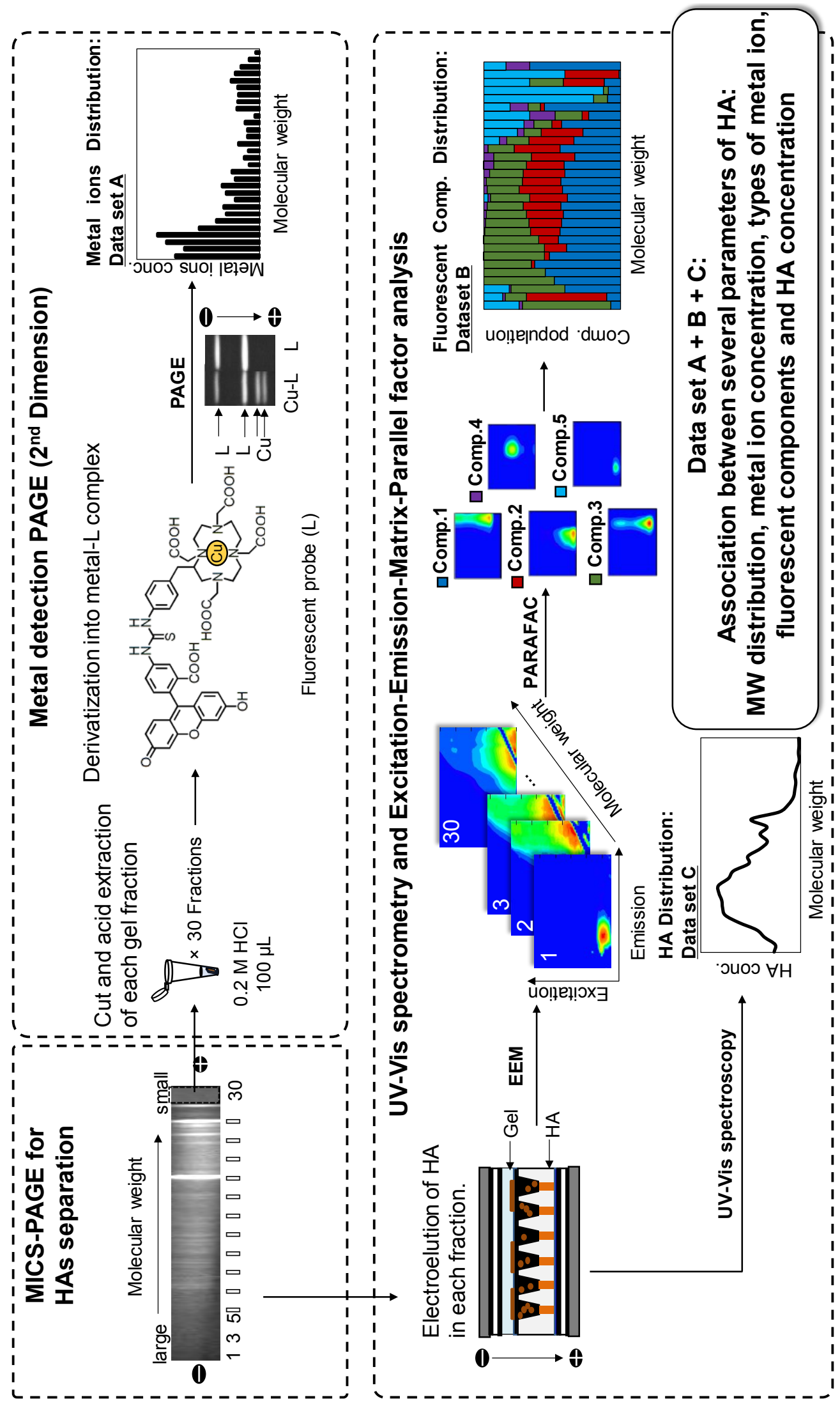

Figure S1. Outline of our MICS-PAGE/metal-detection PAGE/UV-Vis/EEM-PARAFAC methodology. 


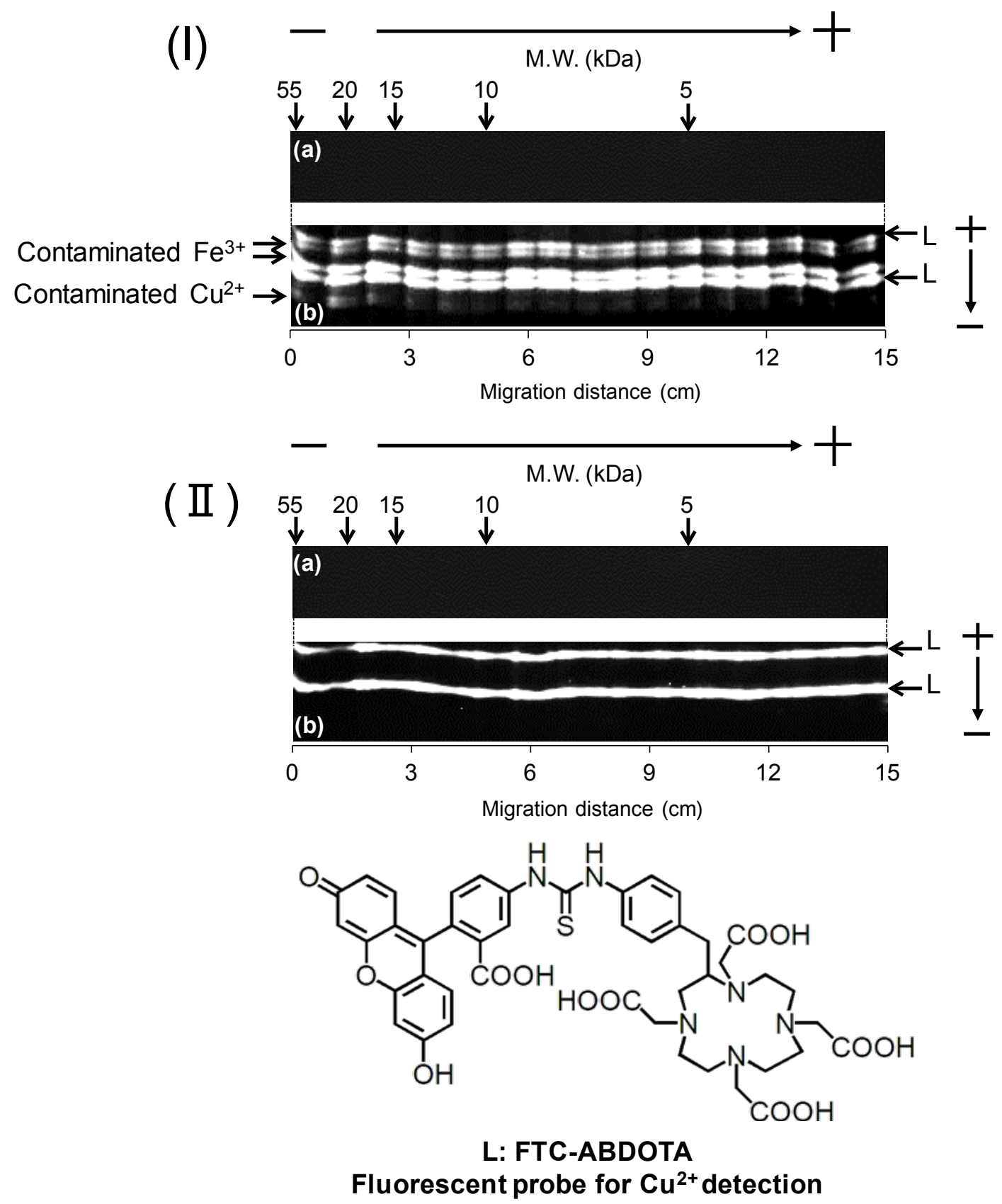

Figure S2. Electropherograms for HA separation PAGE (a) and metal-detection PAGE (b) for an ultrapure water sample: (I) conventional PAGE without the MICS mode and (II) MICS-PAGE. Fe-L: fluorescence bands of $\mathrm{Fe}^{3+}-\mathrm{FTC}-\mathrm{ABDOTA}$ complex, $\mathrm{Cu}-\mathrm{L}$ : fluorescence bands of $\mathrm{Cu}^{2+}-\mathrm{FTC}-\mathrm{ABDOTA}$ complex, $\mathrm{L}$ : fluorescence bands of free FTC-ABDOTA. 


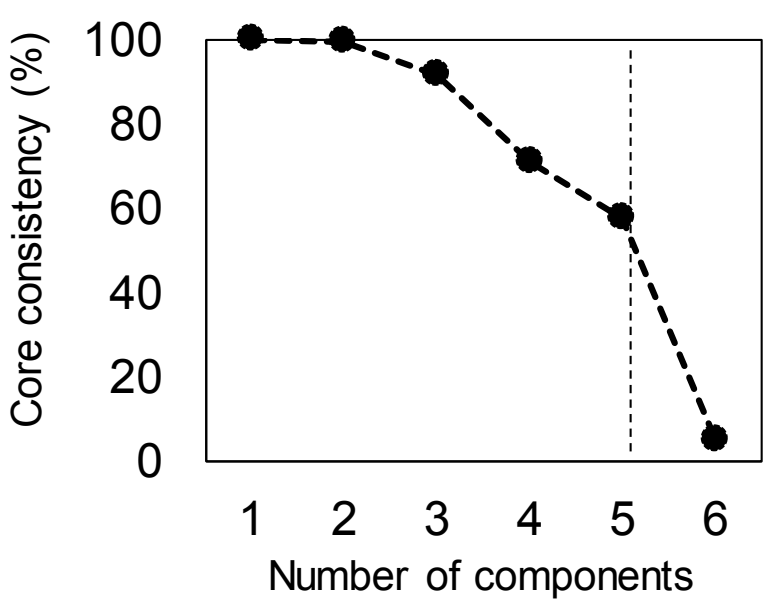

Figure S3. Core consistency as a function of the number of components in PARAFAC modeling.
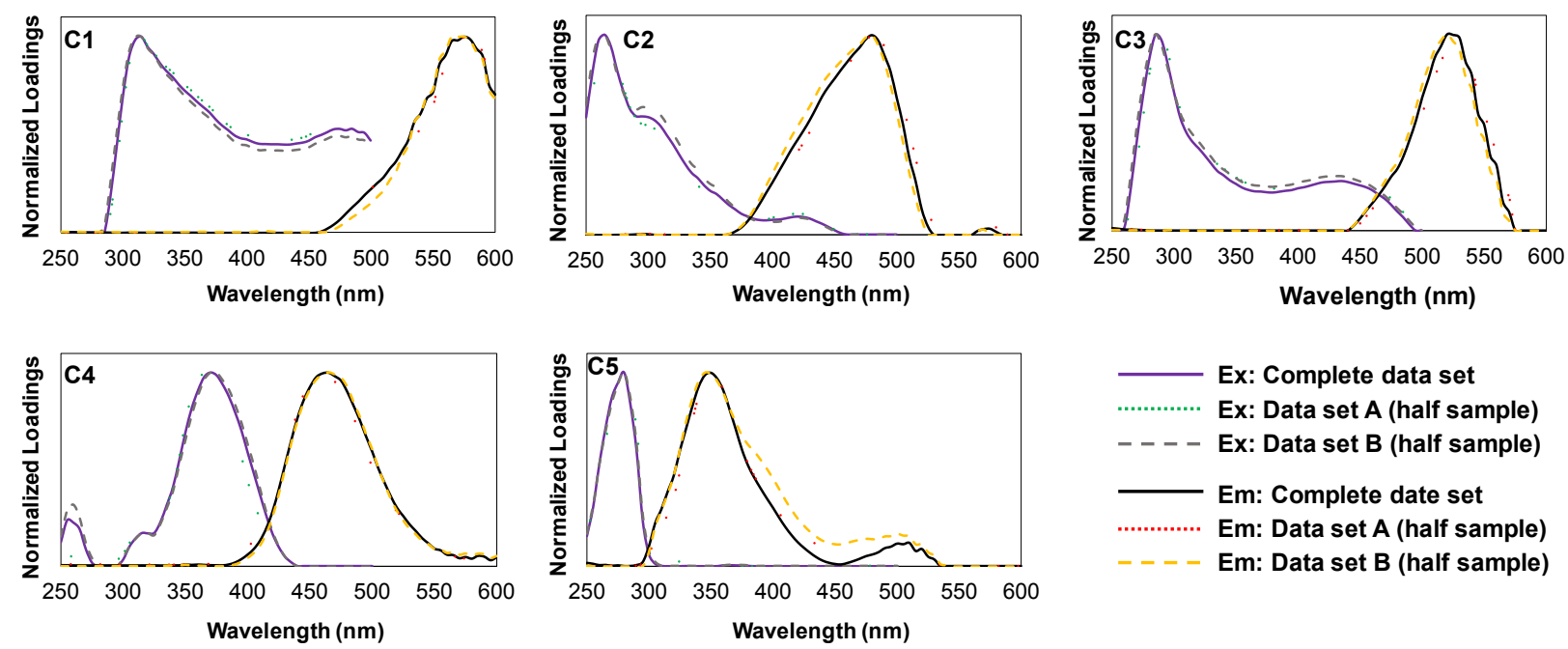

Figure S4. Results of the split-half analysis of our data sets. The split-half was performed by dividing the complete data set into two subsets depending on the origin and addition of $\mathrm{Cu}^{2+}$; Data set $\mathrm{A}$ consist of PAHA, $\mathrm{Cu}^{2+}-$ DHA, $\mathrm{Cu}^{2+}-$ IHA and LHA. Data set B consist of $\mathrm{Cu}^{2+}-$ PAHA, DHA, IHA, and $\mathrm{Cu}^{2+}-$ LHA. 
DHA

M.W. (kDa)

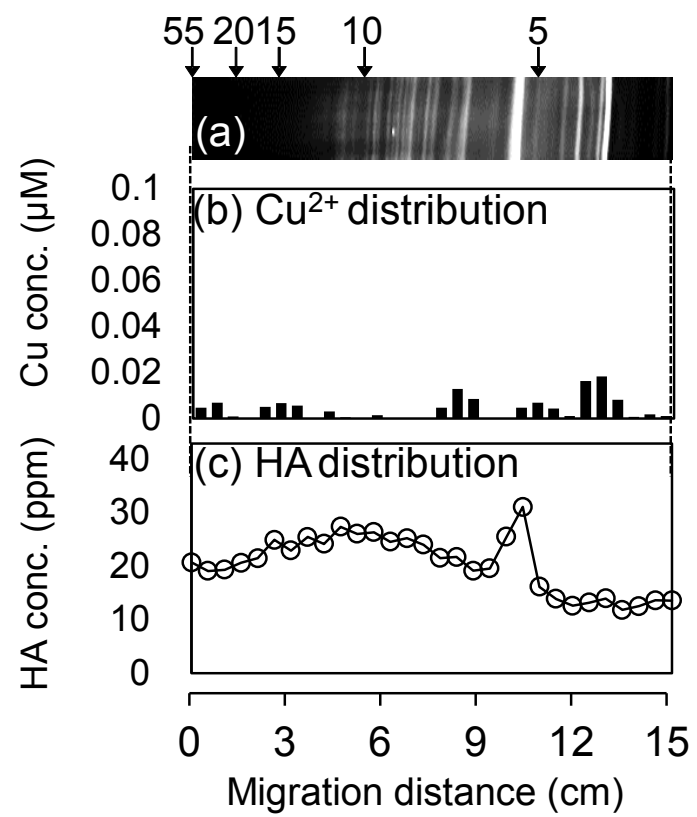

IHA

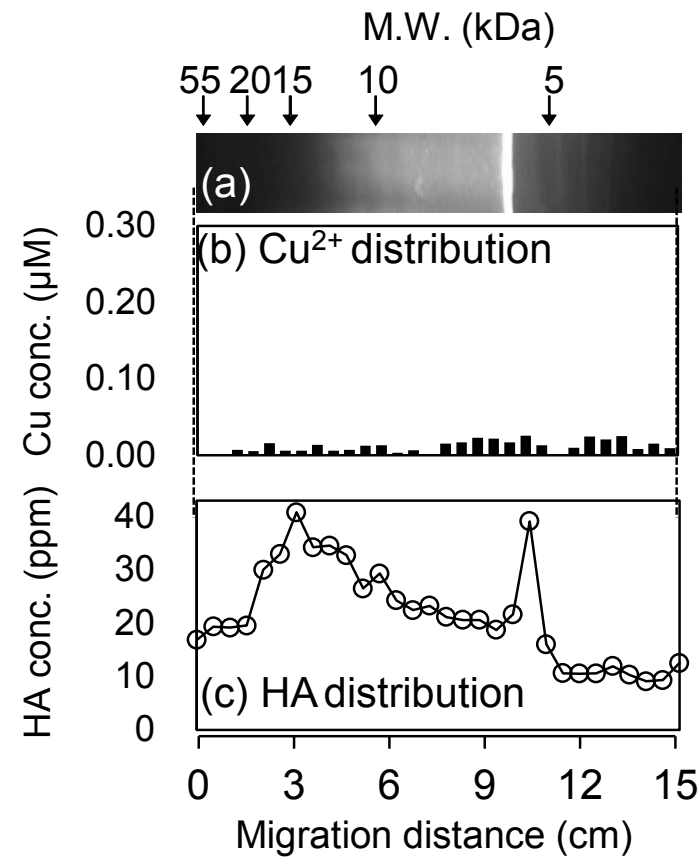

$\mathrm{Cu}^{2+}-\mathrm{DHA}$

M.W.(kDa)

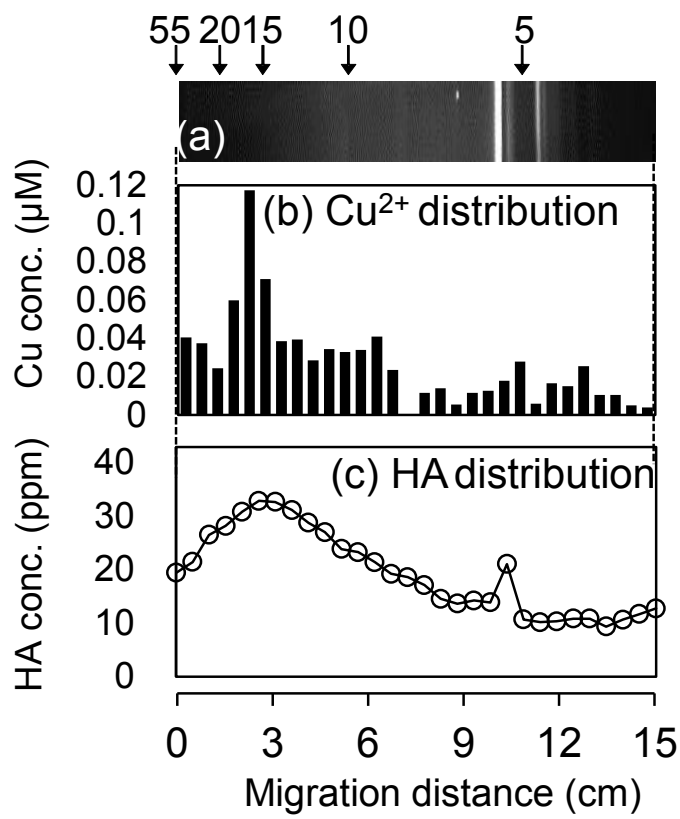

$\mathrm{Cu}^{2+}-\mathrm{IHA}$ M.W. (kDa)

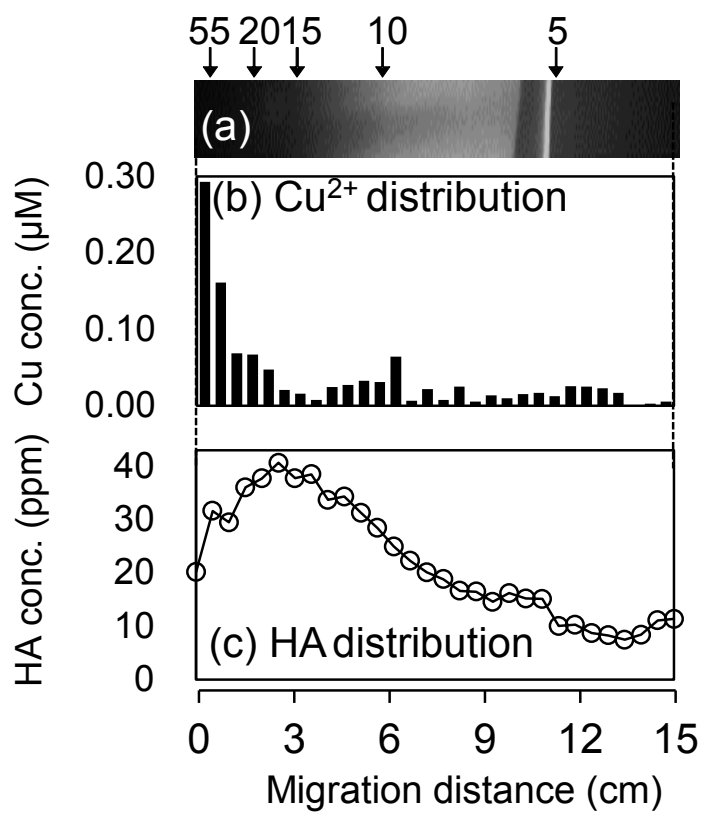



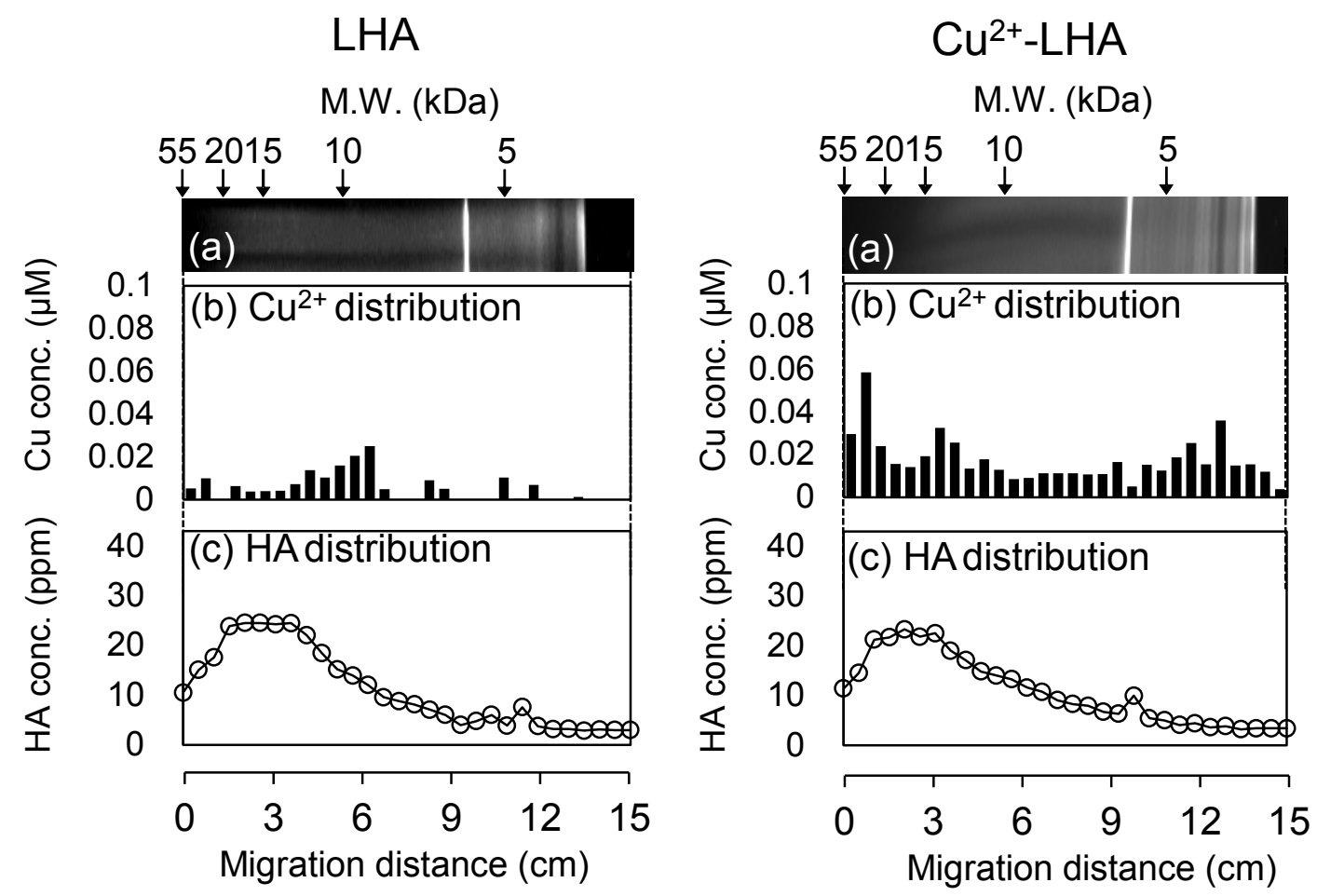

Figure S5. Typical MW distributions of $\mathrm{Cu}^{2+}$ for each DHA, IHA, and LHA without (left) or with added

$\mathrm{Cu}^{2+}$ (right). (a) Electropherograms with fluorescence detection, (b) $\mathrm{Cu}^{2+}$ distributions measured by metaldetection PAGE, and (c) HA distributions measured by UV-Vis spectroscopy. Sample: [HA] = 50 ppm, $\left[\mathrm{Cu}^{2+}\right]=0$ or $4 \mu \mathrm{M},[$ Tris- $\mathrm{HCl}]=60 \mathrm{mM}, \mathrm{pH} 7.4$. 

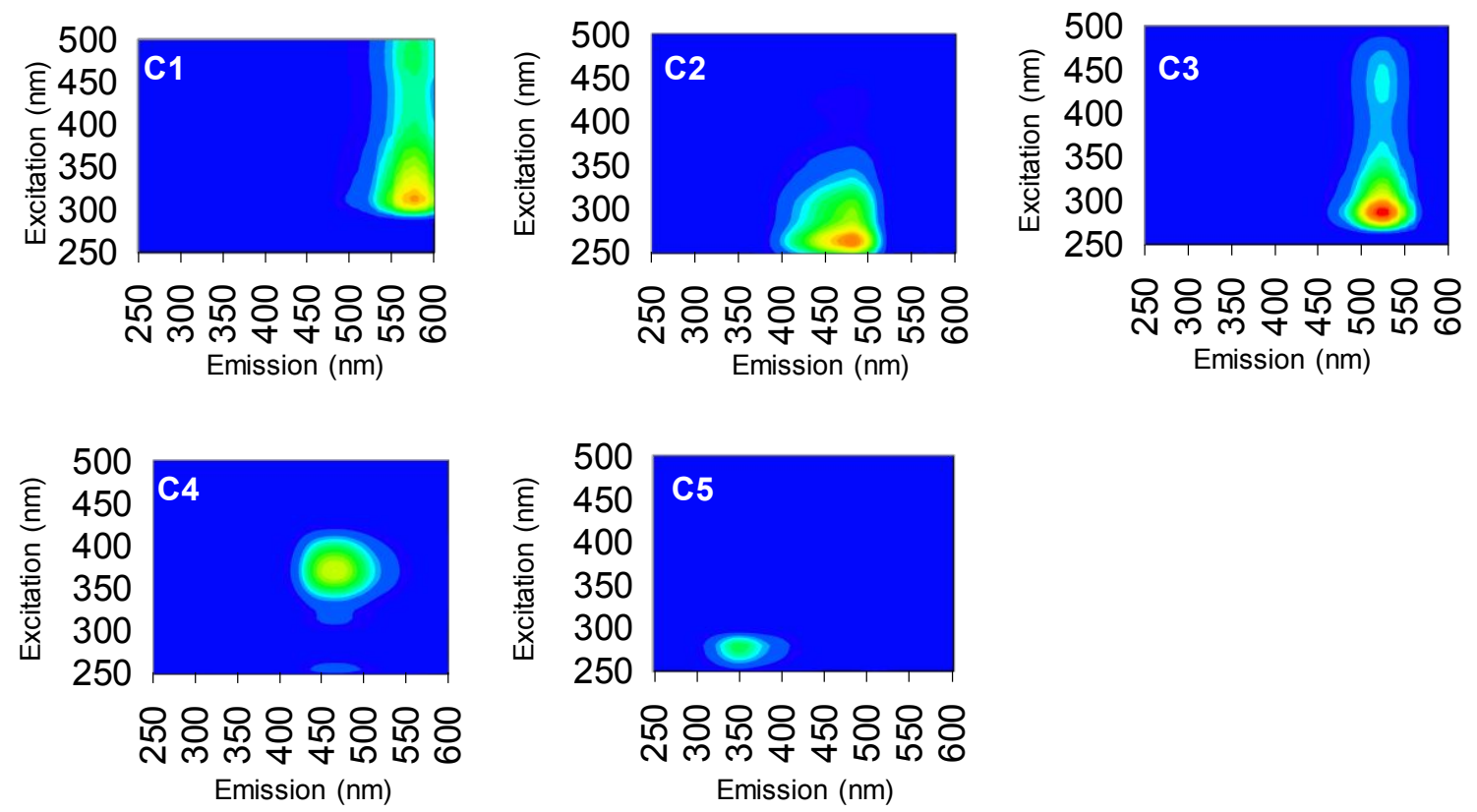

Figure S6. EEM spectra of the five florescent components obtained by MICS-PAGE/EEM-PARAFAC. 
a)
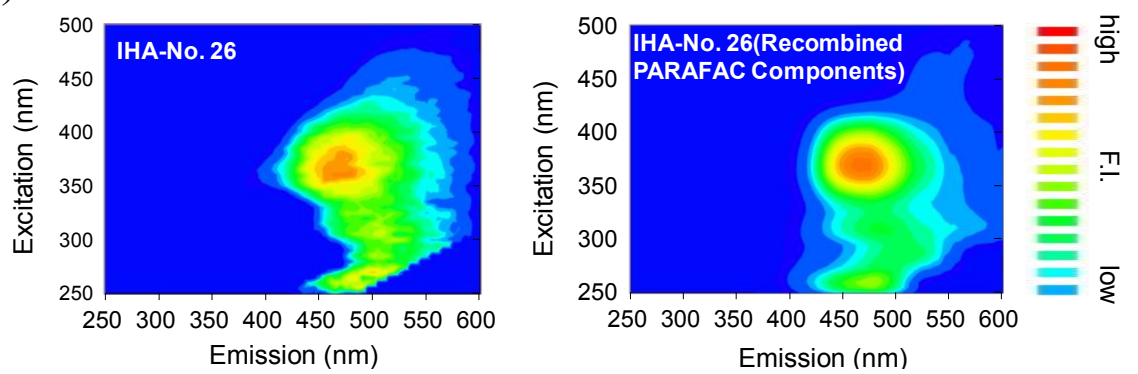

b)

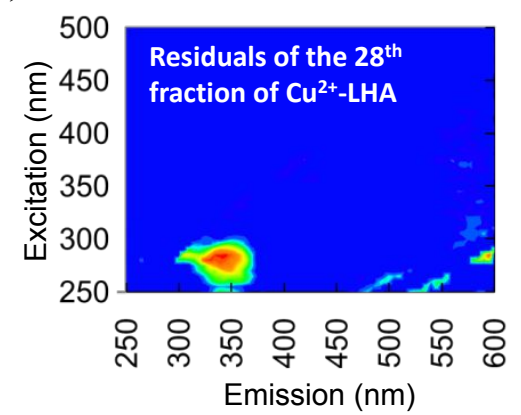

c) IHA, original EEMs

IHA, residual EEMs

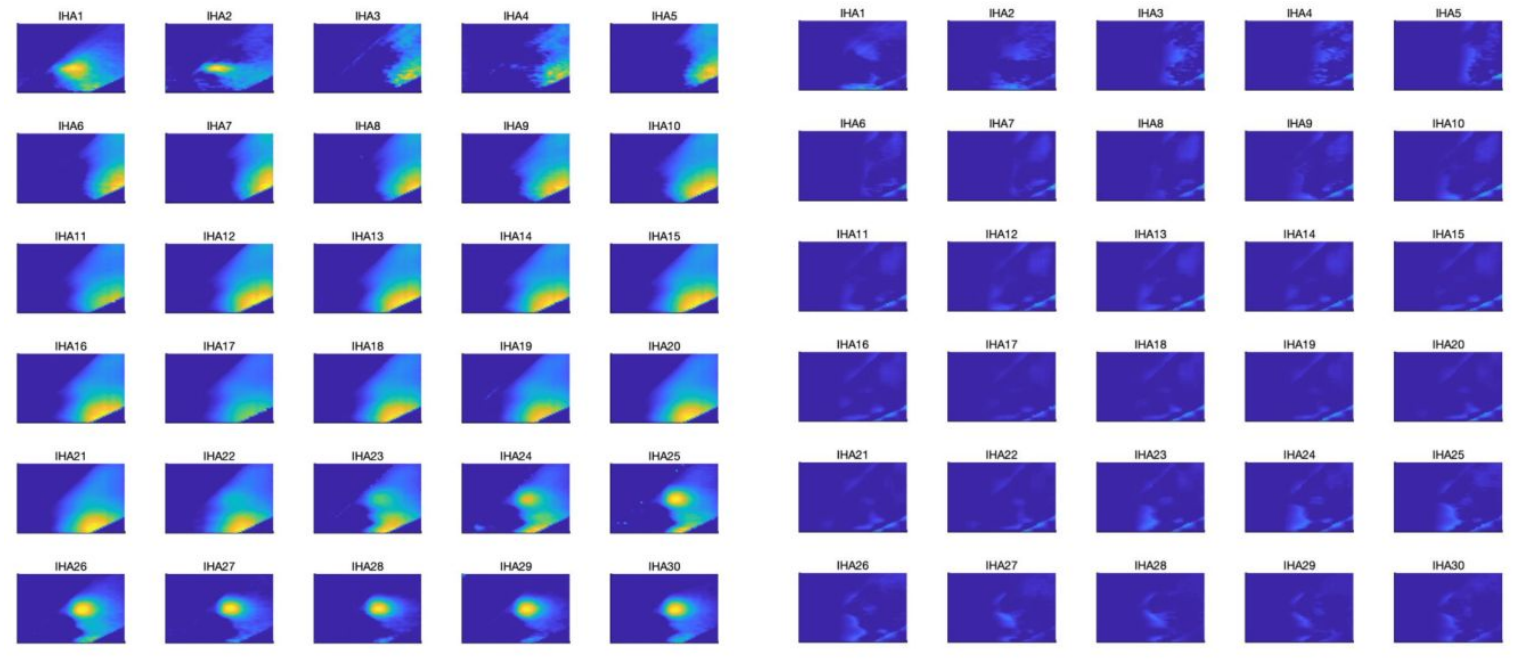

Figure S7. EEM spectrum of the $26^{\text {th }}$ MW fraction of an IHA sample (a, left) and EEM spectrum obtained

by recombining the five PARAFAC components for this fraction (a, right), a residual EEM of the 28th

fraction of $\mathrm{Cu}^{2+}$-LHA using four-component PARAFAC model (b), and residual EEMs compared with

original EEMs for IHA (c). The residual EEM in (b) showed protein-like component was significantly

observed as residual error. 

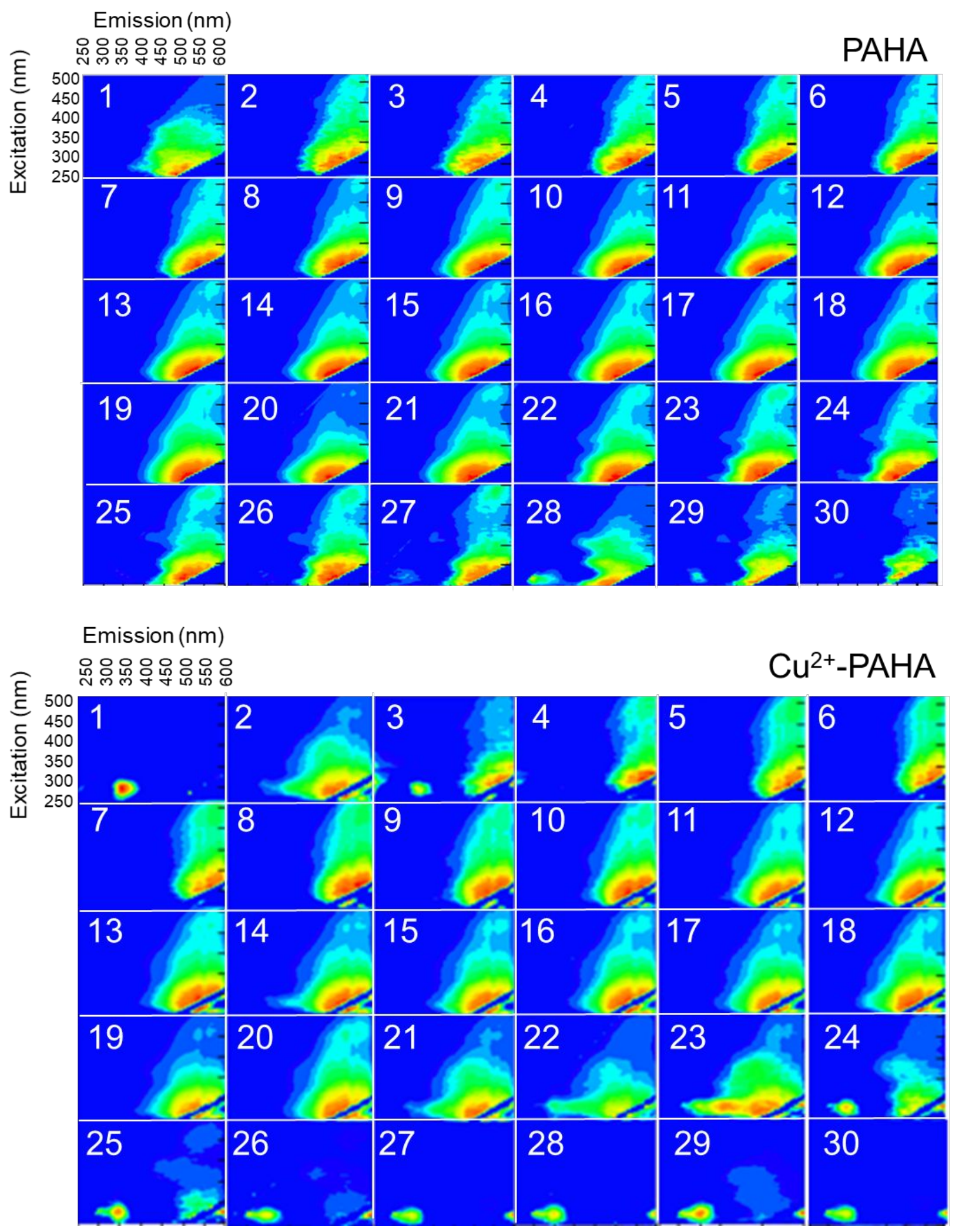
Emission (nm)

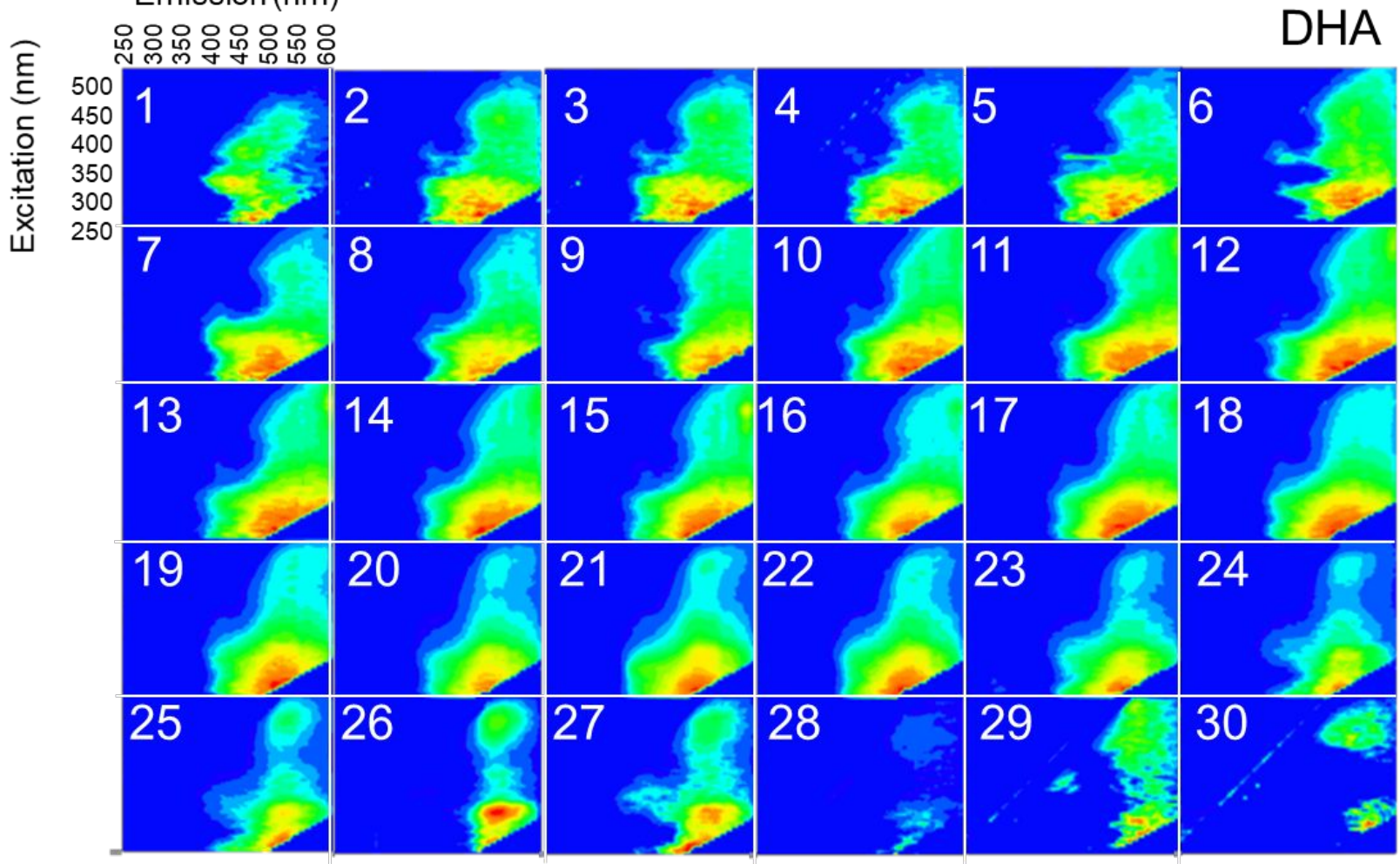

Emission (nm)

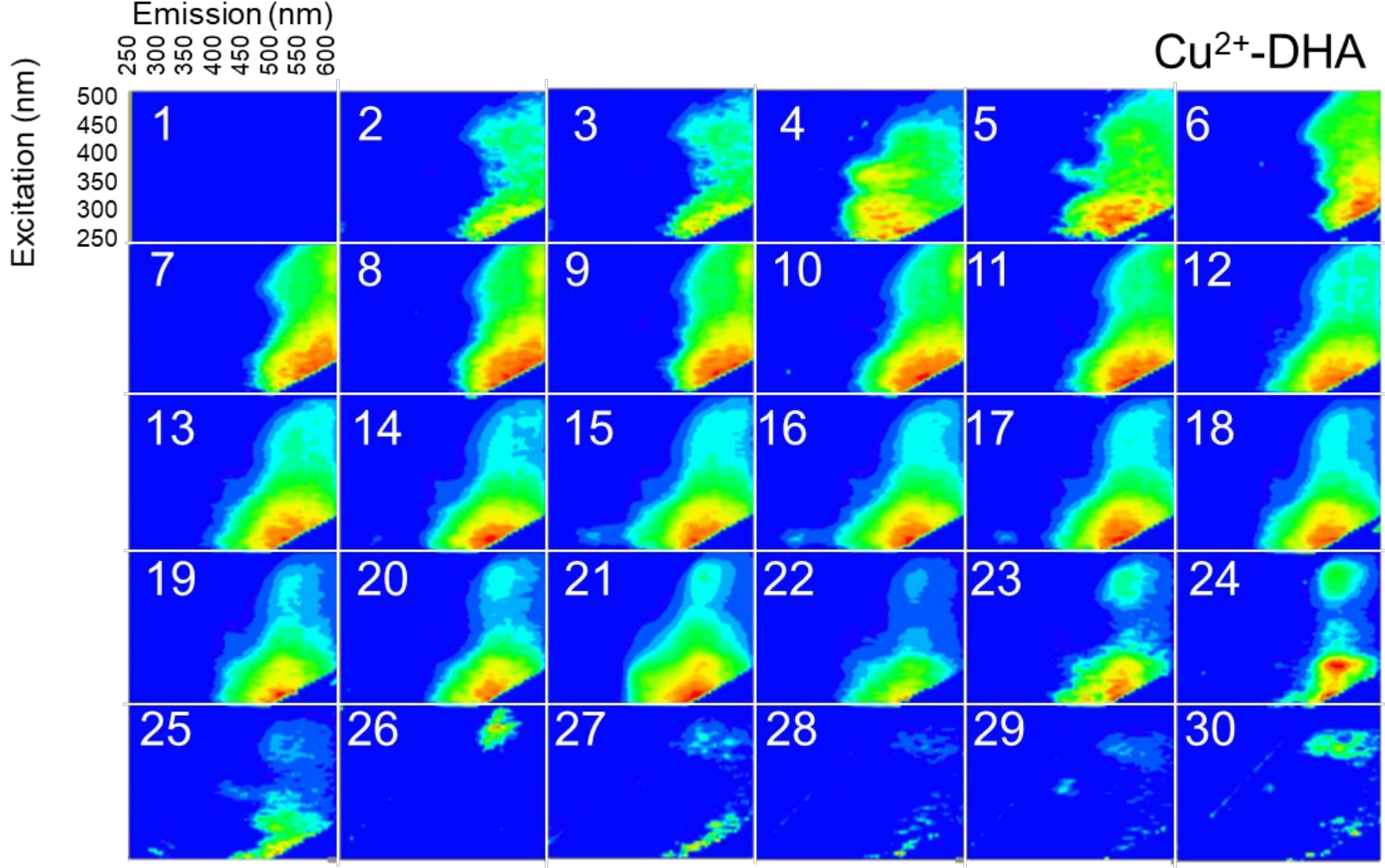




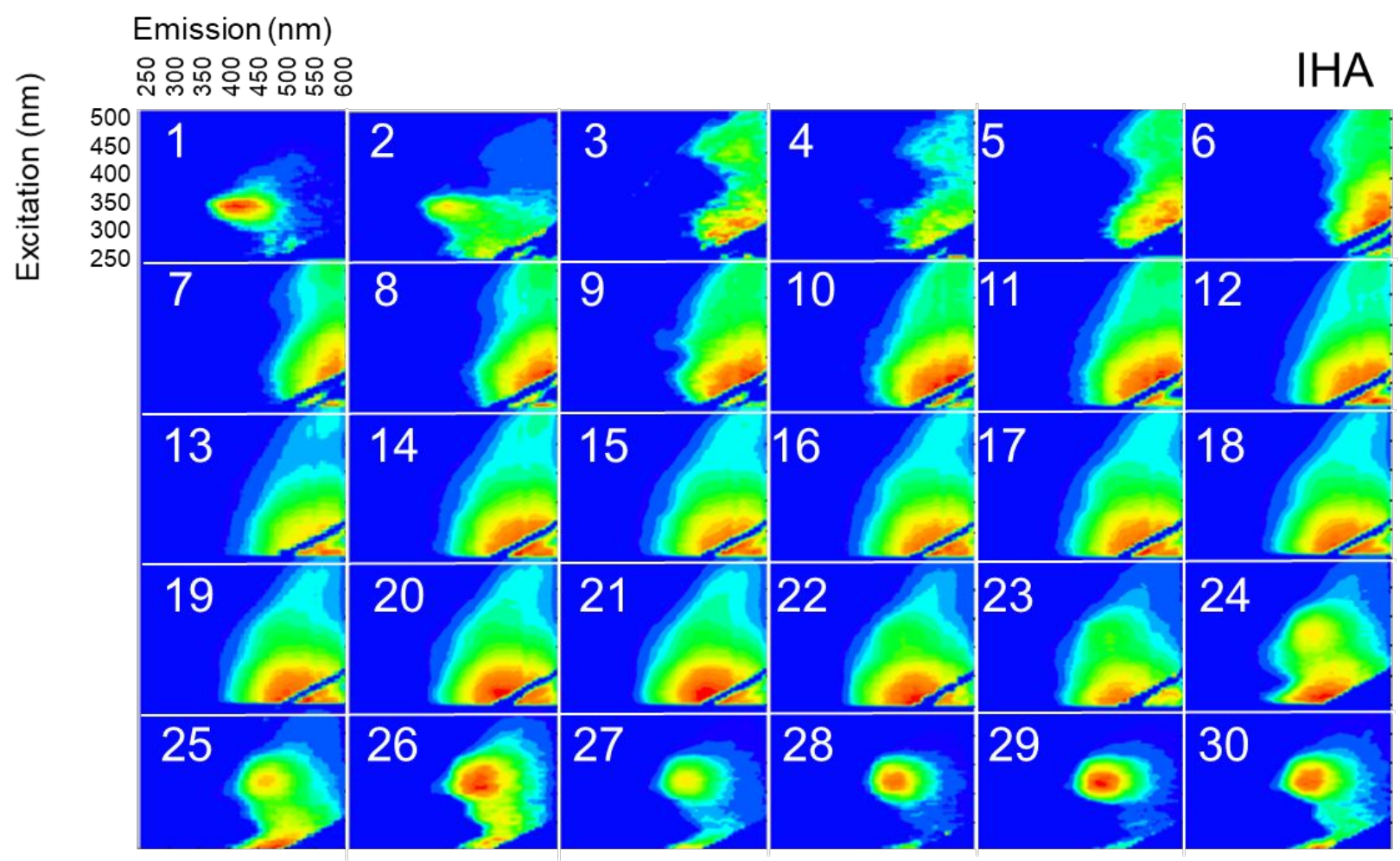



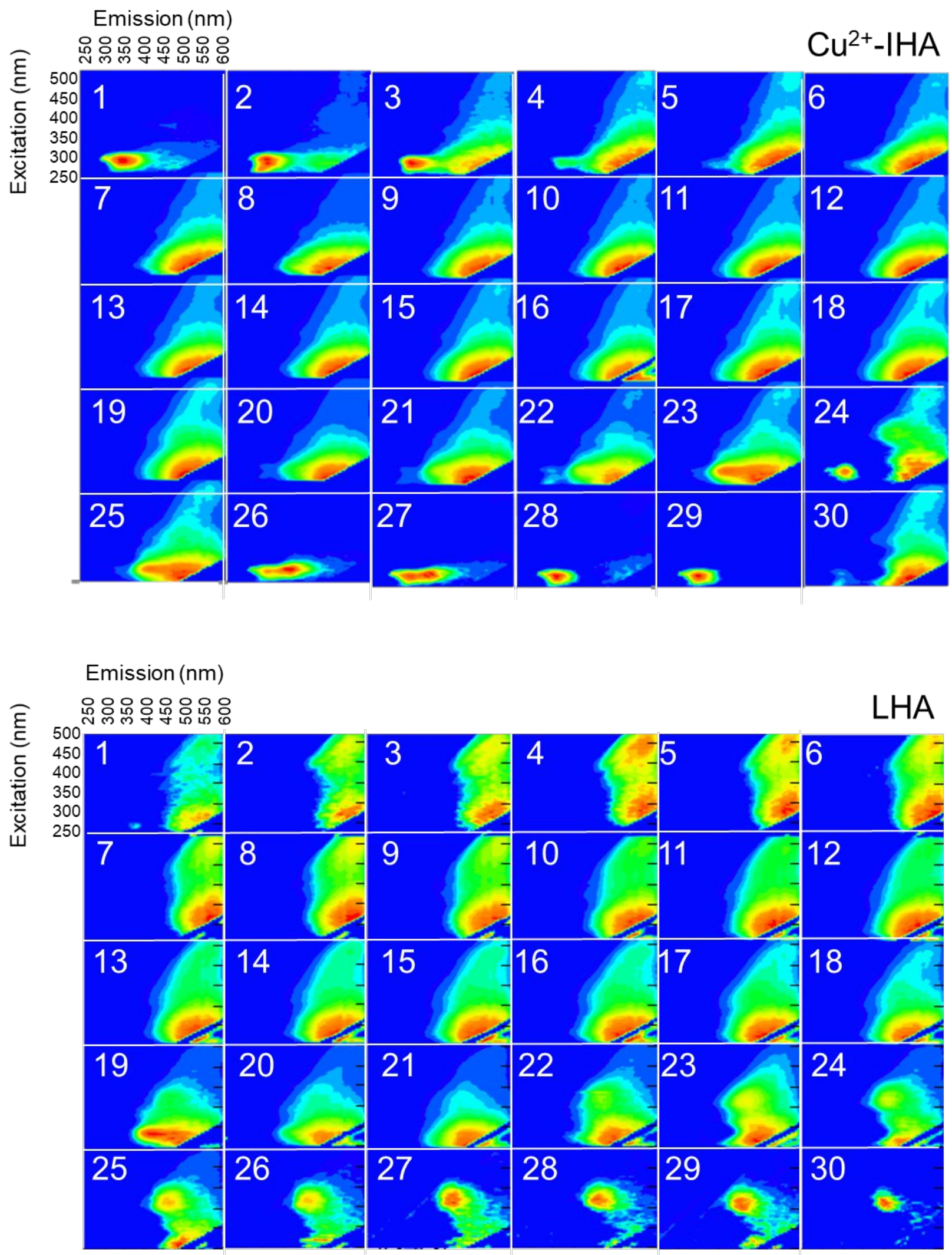


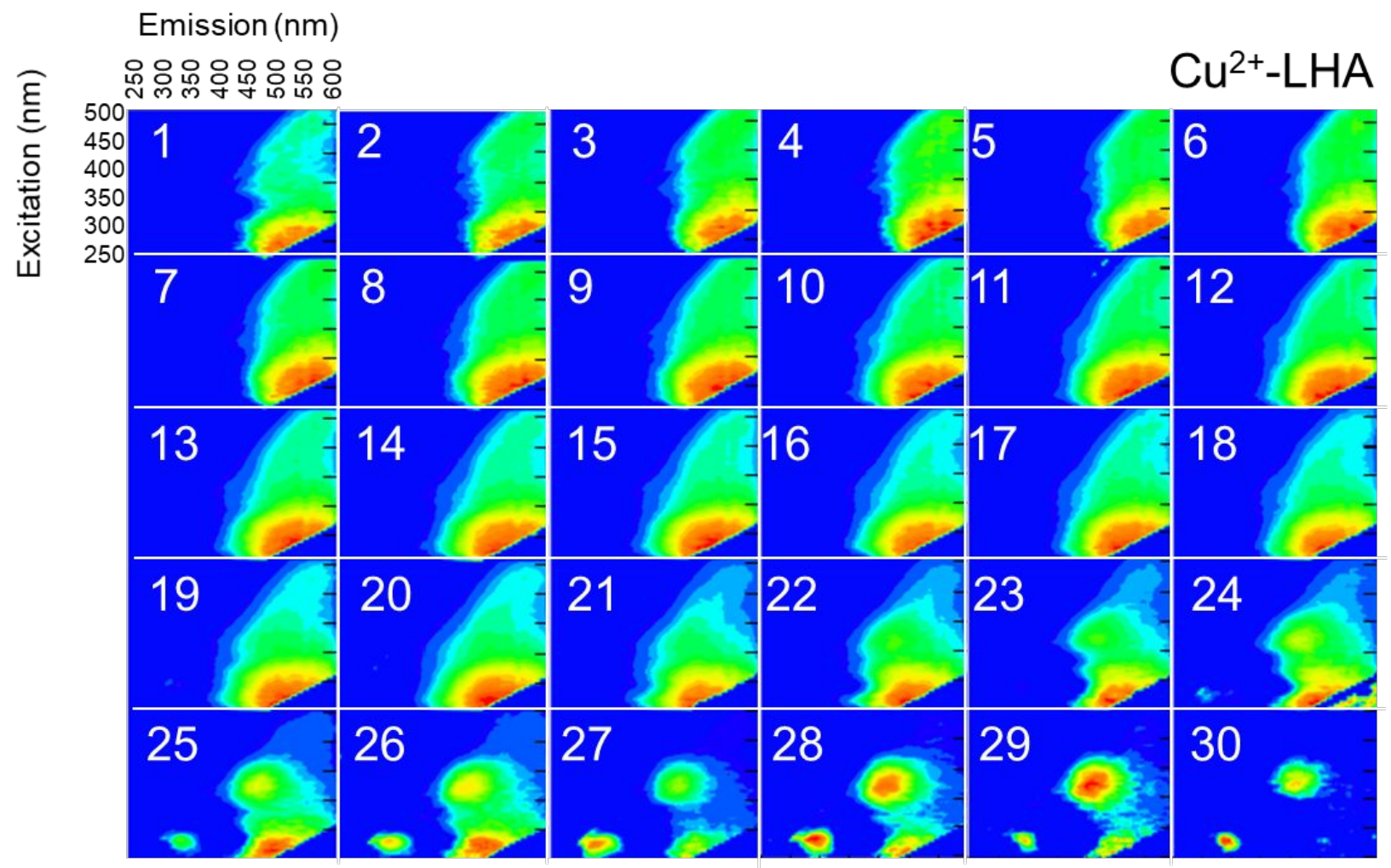

Figure S8. EEM spectra for HAs and $\mathrm{Cu}^{2+}$-HA complexes for PAHA, DHA, IHA, and LHA. 

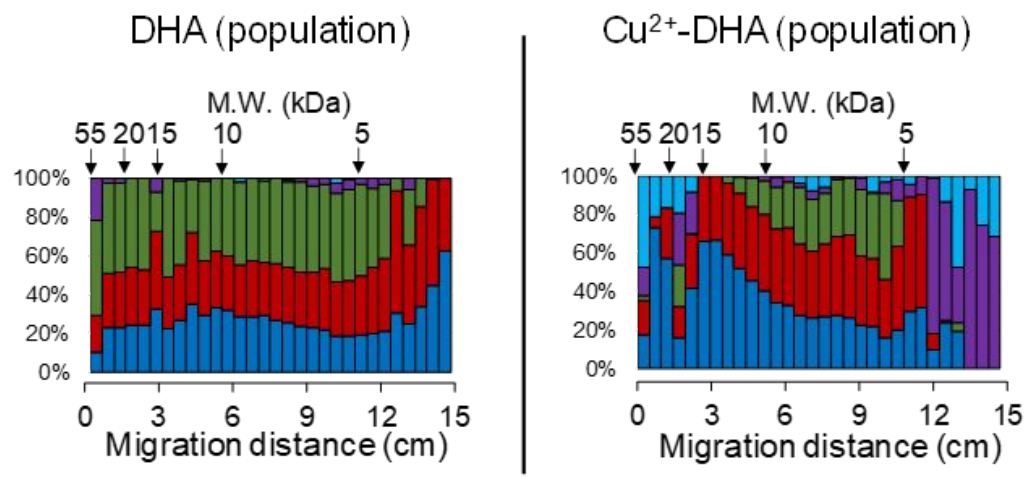

$\mathrm{C}_{1} \square \mathrm{C} 2 \square \mathrm{C} 3 \square \mathrm{C} 4 \square \mathrm{C} 5$

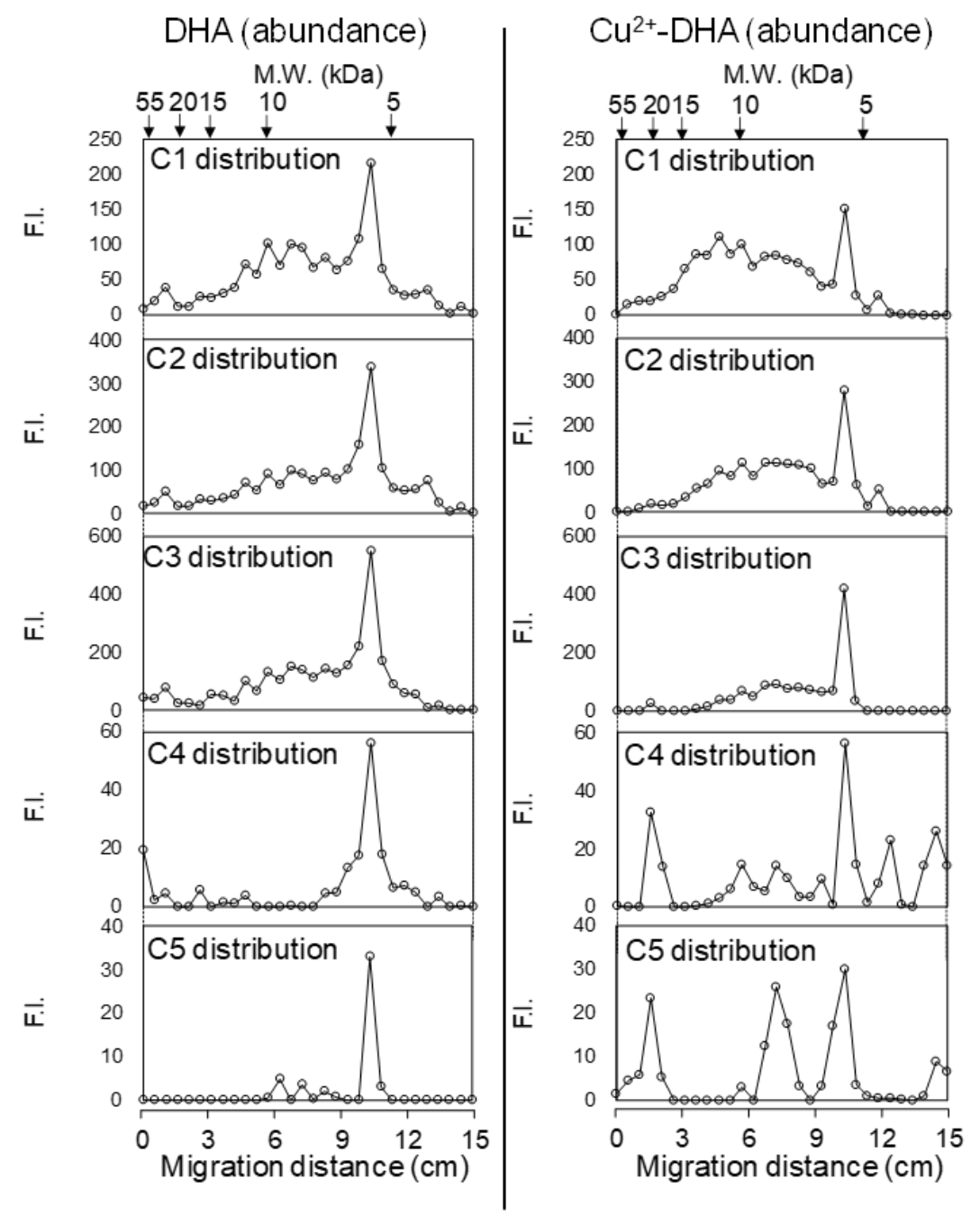



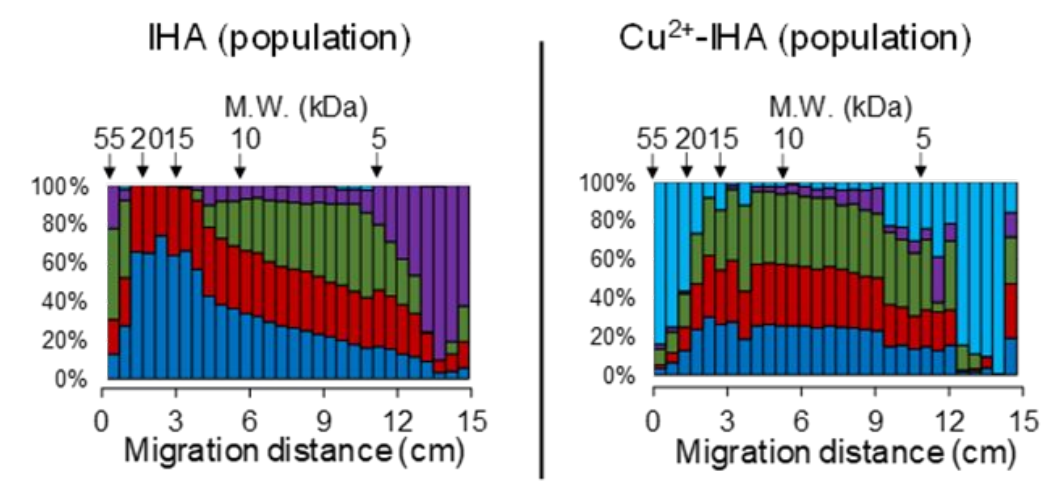

$\square \mathrm{C}_{1} \square \mathrm{C} 2 \square \mathrm{C} 3 \square \mathrm{C} 4 \square \mathrm{C} 5$

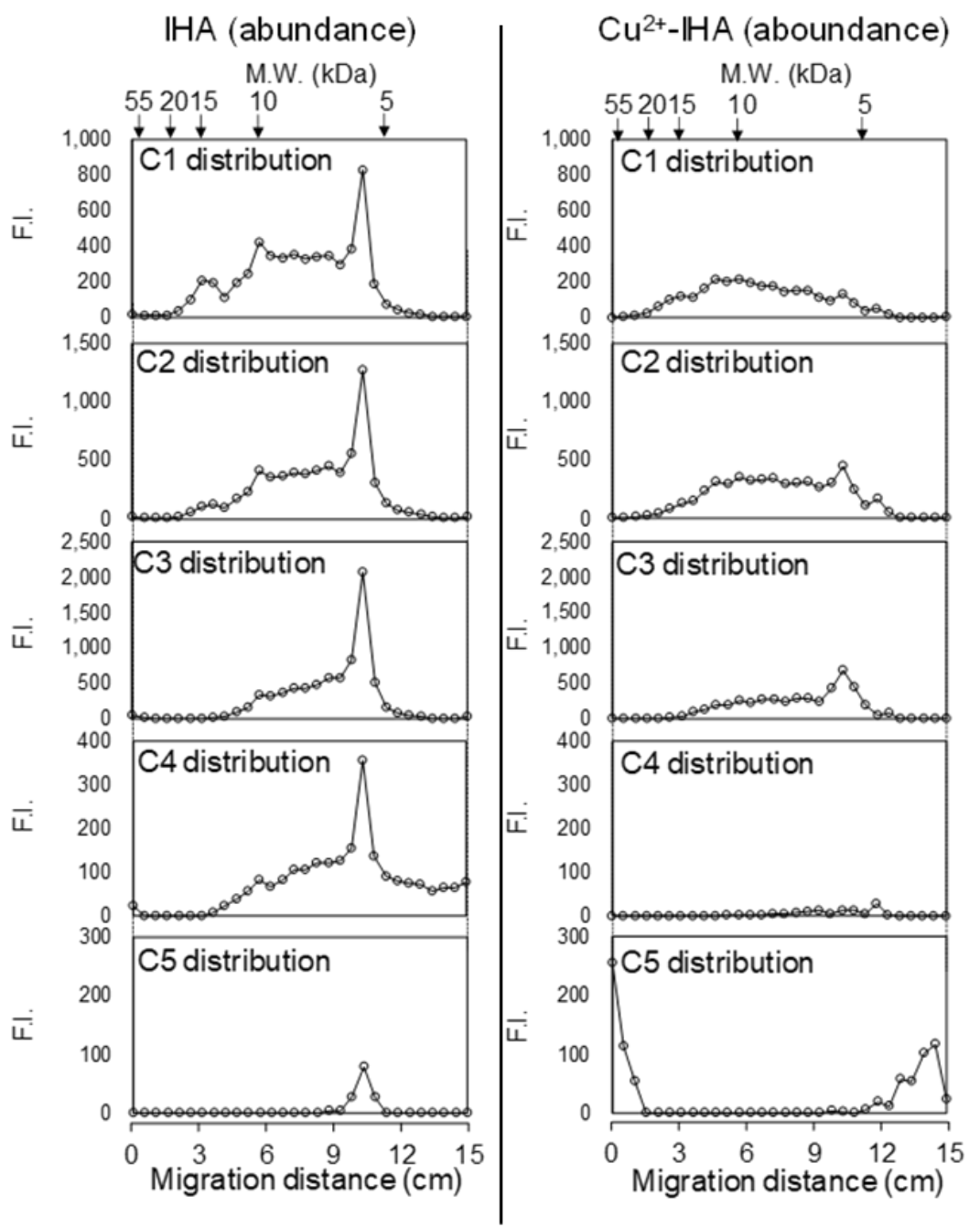




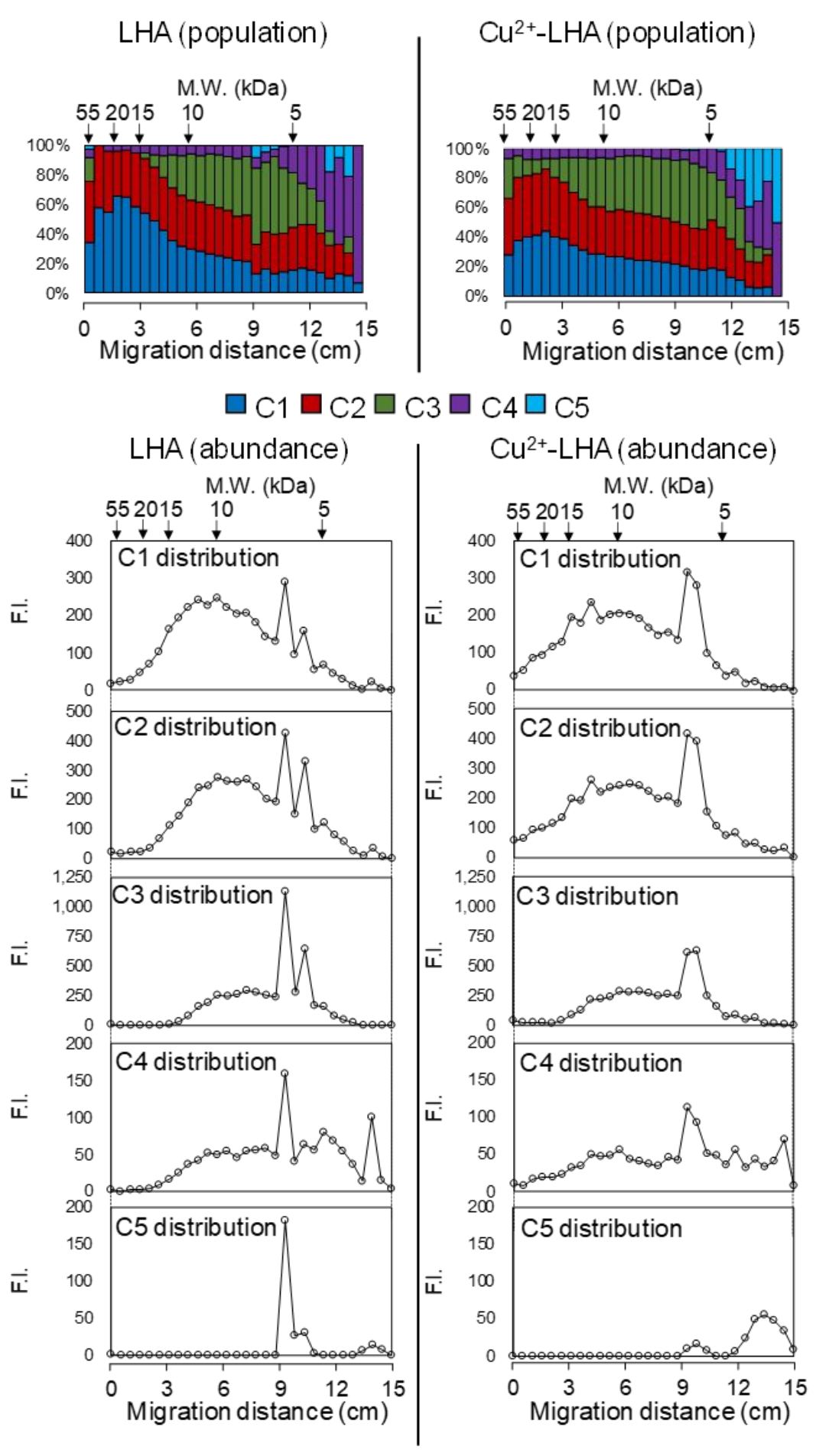

Figure S9. Populations and abundances of the five fluorescent components in each MW fraction for DHA,

IHA, LHA, $\mathrm{Cu}^{2+}-$ DHA, $\mathrm{Cu}^{2+}-\mathrm{IHA}$, and $\mathrm{Cu}^{2+}-$ LHA. 